\title{
The Movie World in Woody Allen's Eyes
}

\author{
Lu Zhang \\ School of Communication \\ Zaozhuang University \\ Zaozhuang, China 277100
}

\begin{abstract}
Woody Allen is a representative of Hollywood's "literary directors", research on whose work has mainly concentrated on analysis of the narrative structure and urban culture of his films in recent years. For example, The Space Narrative of Woody Allen's Films by Dai Bojun, Daily Narrative of Woody Allenby Ranran and City Image in the Woody Allen's Films by Sheng Hanqi etc., these papers, from the perspective of the films themselves, specifically analyze the unique audiovisual features of Woody Allen's films. The research priorities of this paper are to use his films Midnight Barcelona and Mhere Atch Point as an example. It starts from how to create a three-dimensional and typical shaping of the "personal images", and compares the male and female characters in the two films. It also deconstructs the narrative strategies of Woody Allen's films, and combines feminist criticism and the "mirror stage" theory of Lacan. From the multi-cultural perspective, it interprets Woody Allen's films based on the "people" and "personal relationship", and puts forward the intertextuality of between character shaping on the one hand and theme expression, and between narrative strategy on the another hand and theme expression. It also proposes realistic expression of human's desire for "primitive life."
\end{abstract}

Keywords-Woody Allen; intertextuality; male images; female images

\section{INTRODUCTION}

Woody Allen, known as Allen · Stewart · Corney Osborne before, was born in a poor Jewish family on Dec.1, 1935 in Brooklyn, New York. As early as 1968, he dabbled in the film circle, and formally produced the films in 1969.

In his early works, most of the films were comedy films with funny compositions, which showed a place - New York, where Woody Allen worked and lived. He earnestly loved the city in the lifetime of Woody Allen. In a manner of speaking, this city not only records the growth of Woody Allen, but also records the occurrence and development of his films.

The films "Midnight Barcelona" and "Mhere Atch Point" are the relatively later creations of Woody Allen, and more adjacent to reality in artistic performance. Meanwhile, both of the films pay more attention to modern young people's attitudes and behaviors towards romance. If Woody Allen's pre-production is more like "playing art", and then his later works expresses more his thoughts on the return of life and realistic presentation.
The expression of urban cultures and urban ideas in many works directed by Woody Allen are an emblem for him to manifest reality and deliver realistic meanings. In these two works, Woody Allen's choice of the city is no longer limited to New York, but the lenses in his films are extended to Europe. For example, Spain in Midnight Barcelona and London and England in Mhere Atch Point are scenically important places for these two films. Woody Allen's understanding of urban and realistic expression is unique and individual. In his philosophy, young people's emotions are inseparable from the space of life that gives them different kinds of life thinking and choices. His films are apparently the audiovisual expression in different cities, but its connotations present symbolizing expression of urban emotions.

However, inevitably, Woody Allen's film culture has all long insisted on: further explanation and interpretation of American and American culture. The change of narrative space, from New York to Spain, and to London England, contributes to exotic charms of Woody Allen's films. However, the cultural transmission center of the film works has not changed: it is still "very American" and "very modern". Whether it is Vicky and Christina in Midnight Barcelona or Rice in Mhere Atch Point, all these young women are young artists from the United States who share the same nationality and cultural backgrounds, which are familiar to the director Woody Allen. At the same time, they are the representatives of young people he is concerned about.

Woody Allen is crowned as the "national treasure-class person in America", and his works have not only scored fabulous achievements in the North American market, at the same time, but also earned favor on the European continent, achieving remarkable results. Woody Allen, however, is still a one hundred percent New Yorker even if he is changing, innovating and seeking. His heart has been all long concerned about his hometown - New York, but now, he is not just concerned about the city itself, but the shifts the perspective to "focus on people."

It can be said that in Woody Allen's mind, the way of artistic expression is changeable, but the interpretation of cultures and thoughts must have his own unified and unique insights. After years of trials and errors, Woody Allen formed his own "cultural identity." 


\section{WOODY ALLEN'S “INTERTEXTUALITY” ON ARTISTIC EXPRESSION}

There are numerous kinds of artistic expression in the films, but there are not much gaudy artistic skills in Woody Allen's films. However, he chooses a unique manifestation mode to highlight the selection and shaping of person character in the films.

In these two films, Woody Allen's selection and shaping of person images are neither established, nor deliberately arranged, but he expresses the personal images through urban culture, narrative space-time, film languages and other means.

\section{A. Urban Culture}

In the aforementioned discussion of Woody Allen, this paper has already simply mentioned the Woody Allen's preference for urban culture. In these two films, he still chooses a city with different kinds of flavors to display his cognition of romance.

Woody Allen selects Spain as the shooting place for the film Midnight Barcelona, a city with enthusiasm and ebullience, where the audiences are influenced by the free expression of romance. However, these kind of urban cultures under the camera of Woody Allen have emerged as an excellent "character shaping element" that can contrast and shape people, forming the "intertextuality" of personal character shaping.

Wiki is a cultural youth from the United Stated in the film, and her conservatism seems to be against the grain in the mapping of this free city. Such great contrasts make the audience fall into thinking about the fate of the characters. Director Woody Allen wields the "intertextuality" literarily used to describe "city and character" to further characterize Wiki, and at the same time, it also forms underlay and hints consistent with preambles for the next development of the story. Will it be plain sailing for this inarticulate and conservative Wiki in her path of love in this unrestrained and passionate country? The answer is Wiki's the reunderstanding of love.

In the another film Mhere Atch Point, the preciseness of British character is amplified from the details in the film, so the audiences see the majestic British opera house and the quietly suffocating oil painting exhibition instead of the Spanish free galleries and the relaxed guitar minor. This industrial suffocation draws a sharp contrast with the film character, the American drama actor Rice. Urban culture has also become a symbol of the expressing the film culture, which forms the "intertextuality" with character portraying.

As it were, director Woody Allen embraces an actual interpretation of urban cultures. Thanks to this accuracy, he is better able to display the fate of American young people's fate of love and life in different kinds of cultural backgrounds, and effectively use of this kind of urban cultural affection to shape and contrast the characters in the drama, forming the "intertextuality" of character shaping and urban expression.

\section{B. Post-modernity in Narration}

In the post-modern culture, the pursuit of the cultural text structure of "fragmentation" and "collage" has also become one of the narrative ways that the director of Woody Allen expresses the film. In the expression of the narrative space and time of the movie Midnight Barcelona and Mhere Atch Point, the director has a fabulous understanding and audiovisual expression of postmodern narrative features.

In the film Midnight Barcelona, the protagonist does not appear according to a reasonable plot, and everything happens as if it is accidental. It just seems like the surprise of Wiki and Antonio's accidental romance, not a rational arrangement, but a paragraph connection. The instability of this narrative also indicates and reflects the emotional instability and randomness of the protagonists. While forming a personalized narrative style, the emotional expression and fate of the characters are placed in the inside of narrative, forming an intertextuality of internal and external structure of narrative. All these help the audiences to better understand the image-building and emotional expression of characters in the film.

Such a montage narrative allows each story section to be self-contained without the need for more contextual connections. Just like the protagonist's life in the film, it is filled with accidents and uncertainties, but in the end it can escape from the inner greed and torture, and return to normal life and fate. I have to say that in theme expression of many films, director Woody Allen gives the "human" the desire for primitive life, and also counterintuitively gets rid of many of the shackles and restraints of the real society, which forms unique thinking of his films about life and about how do people live and choose.

In the film Mhere Atch Point, the encounter and acquaintance between and Wilton - the male protagonist and Rice - the female protagonist itself is on the "moral judgment frame". It is not the traditional meaning of mutual consent, but is an emotional exploration against ethics. The arbitrariness of narrative also symbolizes the loneliness and panic of the personal character and its maximum pursuit of desire.

The most unexpected thing is that Woody Allen's handling of the end of the film, which is more absurd, irrational, and even ironic. When Wilton murdered his "lover" Rice, the director did not let Wilton, a man who had a considerable desire, receive the punishment he deserved. This narrative against reality is more like a silent resistance against reality and contempt of real authority.

I have to say that in these two films of Woody Allen, the director has planted a seed of yearning for freedom in the heart of every character in the film. This seed is also arbitrarily and irrationally bloomed in the post-modern urban culture, but this disorderly post-modern logic will eventually wither and fade away in real world. The "fragmentation" and "collage" of the director's narrative structure also means that the endings of the characters in the film are fragmented, forming an intertextuality in the narrative structure and narrative expression. 
However, whether it is the director's interpretation of urban culture or the understanding and application of postmodern culture, Woody Allen wields different kinds of artistic expression to display his own film life to the audience. In particular, his concern for the emotional world of young people in today's society has created a vivid and individual image of male and female characters for the audience.

\section{Male IMAGE IN THE MoviE}

Both male and female images seem to have been endowed with the mission of freedom in the Woody Allen's films. They boldly release their own life energy, and perform "mirror dramas" that are close to reality for the audience.

In these two films, Woody Allen's shaping of the male image still does not break away from the established pattern of Hollywood-type movie. In these two films, the male image is in the dominant position in life decision-making and emotional decision-making. This kind of dominance is not only reflected in the control of male characters on female characters, but also in the role and influence of male images on off-screen audiences.

In the film Midnight Barcelona, Antonio, the male protagonist, has an initiative in sentiment, whether in his encounter with Kristina, or emotional entanglement with Wiki, which are all dominated by Antonio. His uninhibited and unrestrained character attracts the hearts of two women, even if it is the "short fascination" that it is what Wiki says. In the end, both she and her bosom friend Christine choose to compromise and crazily fall in love with Antonio.

In the film Mhere Atch Point, Wilton is also quite free and always takes initiative in the settlement of the emotions between Rice and his wife. When meeting Rice again Wilton's aggressively asking of Rice's phone number foreboded the uselessness of Rice's inner struggle. In the emotional world and choice, the director did not give female characters more expression space, but more emotional obedience.

It can be said that Woody Allen's shaping of the male image in these two films is laced with the color of "patriarchal suppression." In the film theorist Laura's paper Murvey's Visual Pleasure and Narrative Cinema, the author also expounds initiative of men in film shooting.

In his exposition, the initiative of the male image is understood diversely. First, the director and the photographer are generally males in the shooting of the film; second, the female image is often designed as an object of pornography in the narrative of the film, being watched by the male image and the audience, and the male becomes the holder, while the woman is treated as an object, .

In the criticism of feminist films, Nick Brown also said: "Most American films are shot by men, and women become a kind of landscape. From the narrative perspective, American films deem men as dominant, and the women are put in the position of the supporting role." Nick Brown and Laura Murvey's disposition conforms to each other. Director Woody Allen also practices this "watching and being watched" theory in his own films, shaping the male characters in the film as the primitive existence with "mysterious power", which also truly expresses the irregularity of people's pursuit of "desire" and further explores the problem of people living in the emotional world.

However, it is worth pondering that Woody Allen does not simply and blindly pursue this "patriarchal" tradition, but instead accepts male-dominated social reality while giving female characters more room for expression. He "realistically" reproduces the struggle and choice of women in the emotional world, even if the sadness and irreparability of the ending, the growth and courage of the female images are well displayed in his films.

\section{THE EMBODIMENT OF FEMALE IMAGES IN THE FILMS}

In Woody Allen's films, the characters are generally an image of intellectuals with certain of cultural backgrounds, which is better reflected in the female images of the two films. Wiki and Cristina in Midnight Barcelona are young people with high degrees of knowledge, and Rice in Mhere Atch Point is also a progressive youth who loves performance, concentrates on research, and looks for opportunities.

This kind of design of education background emphasizes the status of women in society and in the same time tries to liberate women spiritually. Woody Allen's positioning of the female image is actually to intentionally improve the status of women. Although the dominant position of the male image in the previous section has been clearly defined, the female images in the film are not completely dominated by men. This is also the place where Woody Allen is emotionally entangled, which we can also feel through the stories among the characters in the film.

Shulamith · firestonc, a feminist critic, said: "Women can always find a space for resistance in their life experience and in their own cultural production." As Firestone says, the female characteristics are constantly seeking selfemancipation in the temporary lost in the two films of Woody Allen.

When Christina decided to leave Antonio and his wife, her eyes were so pure and determined, and she seriously felt everything that life endowed her. In the face of misunderstanding of her good friend Wiki and her fiance, she did not pay much attention to their thoughts and feelings, but chose her own freedom and her own life.

Woody Allen portrayed Christina to be against man's power. He objectively displays the spiritual outlook that women's image should have today. It can be said that Christina is the goddess of freedom in Woody Allen's heart, who was shaped as a rebel against the convention and a protester against the reason.

Similarly, Rice's independence and rebellion in her personality in Mhere Atch Point also display the independent spirit of today's women, reflecting Woody Allen's attempts to break the routines. Although the film recognizes the initiative of females from the character design of female 
characters, the end of the film completely disintegrates the female's free images and returns to the chiche where males are in the dominant position.

Woody Allen makes constantly exploration and innovation in the design and shaping of female images. Whether it is for the character shaping or emotional arrangement of female characters, he tries to break the image of women being long-term bound. From the perspective of real life, he uses movie, the unique mirror, to show the colorful side of female characters.

\section{CONCLUSION}

Woody Allen wields his wisdom to constantly focus the camera on the emotional world in real life, and makes audiovisual application of the films based on various ways of expressing culture. Whether in the intertextuality between the characters and the narrative structure, or the traditional and individual expression of male and female characters, Woody Allen describes the cultural expression and thinking of modern young people about the life and survival in different urban culture backgrounds, helping the audience to constantly open up the image space of self-examination.

\section{REFERENCES}

[1] [United States] Hugh. Thornham. Introduction to Feminist Film Theory $[\mathrm{M}]$. Ai Xiaoming, translated. Guangxi: Guangxi Normal University Press, 2007: 78.

[2] History of American Education [M]. Beijing: People's Education Press, 1994: 78. (in Chinese)

[3] Zhang Yibing.The Philosophical Principle of Lacan's Mirror Theory[J]. Fujian Forum (Humanities and Social Sciences), 2004, (10): 36-37. (in Chinese) 